\title{
Design and Performance Analysis of Composite Airfoil Wind Turbine Blade
}

\author{
Hegespo H Mwanyika ${ }^{1,2,3^{*}}$, Yusufu AC Jande ${ }^{1,2}$ and Thomas Kivevele T,2 $^{1,2}$ \\ ${ }^{1}$ School of Materials, Energy, Water and Environmental Sciences, Nelson Mandela African \\ Institution of Science and Technology, P.O. Box 447, Arusha, Tanzania \\ ${ }^{2}$ Water Infrastructures and Sustainable Energy Futures, Nelson Mandela Rd, P.O. Box 9124, \\ Nelson Mandela, Arusha, Tanzania \\ ${ }^{3}$ Department of Physics, Mathematics and Informatics, Dar es Salaam University College of \\ Education, P.O. Box 2329, Dar es Salaam, Tanzania \\ *Correspondence: mwanyikah@nm-aist.ac.tz \\ OtherEmails: yusufu.jande@nm-aist.ac.tz,thomas.kivevele@nm-aist.ac.tz
}

Received 3 Aug 2021, Revised 22 Oct 2021, Accepted 29 Oct 2021, Published Dec 2021

DOI: https://dx.doi.org/10.4314/tjs.v47i5.18

\begin{abstract}
Small horizontal axis wind turbine rotors with composite airfoil rotor blades were designed and investigated in the present study in order to improve its performance in low wind speed and low Reynolds number ( $\mathrm{Re})$ conditions for standalone system. The geometrical and aerodynamic nature of a single airfoil small horizontal axis wind turbine blade curtails efficient energy harnessing of the rotor blade. The use of composite airfoil rotor blade improves energy production but imposes uncertainty in determining an optimal design angle of attack and the off design aerodynamic behaviour of the rotor. This research investigated the effects of two airfoils used at different sections in a composite blade and determined the blade's optimal design angle of attack for maximum power generation. The wind turbine rotor blades were designed using blade element momentum (BEM) method and modelled by SolidWorks software. The SG6042 and SG6043 airfoils were used for the composite airfoil blades. Five wind turbines were designed with rotor blades of design angles of attack from $3^{\circ}$ to $7^{\circ}$. The five wind turbine blades were simulated in computational fluid dynamics to determine the optimal design angle of attack. The composite airfoil wind turbine blade showed improved performance, whereas, the wind power generated ranged from $4966 \mathrm{~W}$ to $5258 \mathrm{~W}$ and rotor power coefficients ranged from 0.443 to 0.457 . The blade with design angle of attack of $6^{\circ}$ showed highest performance.
\end{abstract}

Keywords: composite airfoil, lift-to-drag ratio, pressure coefficient, Reynolds number, design angle of attack.

\section{Introduction}

The energy security and sustainability are among the challenges that face the world and in particular developing countries. It is also observed that energy is directly linked with major global challenges which include poverty alleviation, climate change, environmental and food security (Gökgöz and Güvercin 2018). The conventional energy sources cannot meet all energy needs especially electric energy systems in rural areas (Naumann and Rudolph 2020). Power generation can be improved using renewable energy sources, mainly in remote areas which are uneconomical for grid extension (Amir and Khan 2021). Therefore, small wind turbines which deploy wind resources in remote areas as stand-alone systems can suffice energy needs in rural windy areas (Singh and Gill 2020). 
The small horizontal axis wind turbine blades need specialized airfoils which can deploy wind resources for maximum energy production. The airfoils like S-series designed by the National Renewable Energy Laboratory (NREL) of USA, which can exhibit gentle stall behaviour (Hasan 2017) and the SG604X series for variable speed wind turbine with enhanced lift-to-drag $\left(C_{L} / C_{D}\right)$ ratios (Giguere and Selig 1998) can be used in small wind turbines. The SG604Xseries have shown good performance for simulated rough surface and works well in the Reynolds number of 100,000 to 500,000 (Noronha and Krishna 2021). The other airfoils which are used for small wind turbines are FFA-W-series, RISO-series and DU-series (Ma et al. 2019). The study of SG6043 airfoil, showed it to be of high enhanced lift-to-drag ratio performance in comparison with other tested airfoils at low Re of less than 300,000 (Shin and Kim 2020). Osei et al. (2020) modified the shapes of SG604X airfoils by adjusting the airfoil thickness $(\mathrm{t})$ with respect to the camber size (c) to improve $C_{L} / C_{D}$ ratios and obtained EYO-series airfoils (Osei et al. 2020) for small wind turbines. The three dimensionality, unsteadiness, and flow separation effects in small wind turbines with low Reynolds number flow result into poor efficiency (Jahanmiri 2011, Shah et al. 2012, Canale et al. 2020, Leloudas et al. 2020). A modified small wind turbine rotor which is made of two or more high and medium cambered airfoils is investigated in this research for improved performance.

Single airfoil rotor blade design has been the normal routine for all small horizontal axis wind turbines (Ighodaro and Akhihiero 2021). The airfoil shape and structure do not always suit the blade sectional function (Habali and Saleh 2000). However, few research have been conducted for composite airfoil blades to study their effects in power performance (El-Shahat et al. 2019). Tang (2012) investigated the performance using DU93-W-210 as a baseline airfoil for composite airfoil rotor blade with four subsections of different thicknesses. The blade maintained the baseline airfoil shape from $0.35 \mathrm{R}$ to $0.9 \mathrm{R}$ of blade plan form and the rest were smoothed to match the baseline. A composite airfoil blade was manufactured using S833 for root and middle part and S822 for tip part as result stall was controlled and performance was improved by 2.9 percent (El-Shahat et al. 2019).

The flow behaviour on airfoil surface like detached flow and laminar separation bubble (LSB) are shown using the pressure coefficients which assist to characterise the airfoil structural effects (Hansen 2018). The separation and transition points tend to proceed towards the leading edge of airfoil as the angle of attack increases; also the stall angle decreases with diminishing Reynolds number (Re) (Dong et al. 2019). The angle of attack increase causes the adverse pressure gradient increase on the upper surface of the airfoil which makes the separation point and LSB move towards the leading edge which results into immediate stall increase and poor blade performance (Park et al. 2020). Therefore, optimum angle of attack reduces the effect of flow separation and hence improves aerodynamic efficiency (Singh et al. 2012). In this paper, optimum angle of attack was investigated to improve stalling behaviour and maximise lift for maximum power generation.

In most of the studies, the analysis of small wind turbine system is done by blade element momentum (BEM) method and the computational fluid dynamics (CFD) (ElShahat et al. 2019). The CFD and BEM are used for preliminary design stages since they differ by $6-15 \%$ of accuracy as compared to nominal and experimental results (Castellani et al. 2018). BEM works well with low wind speeds up to $12 \mathrm{~m} / \mathrm{s}$ whereby the CFD can be used for improved precision for an extended range of wind speed up to $20 \mathrm{~m} / \mathrm{s}$ (Perić et al. 2020).

This study investigated on optimal composite airfoil design and associated parameters of the wind turbine rotor using BEM and CFD. The SG604X series airfoils was designed for small variable-speed horizontal axis wind turbines which rates 1-5 kW (Selig 2003). To the best of authors' knowledge, no study has used a composite of 
SG6042 and SG6043 to improve efficiency of a small wind turbine; this was therefore comprehensively investigated in the present study. The combination of the two airfoils for a wind turbine blade necessitated the study of the optimum design angle of attack for maximum power production of the designed hybrid wind turbine rotor blade.

\section{Methodology}

\section{Blade element momentum and optimum rotor theories}

The blade element momentum theory combines blade element theory and momentum theory. Besides many other methods of predicting performance and loadings of wind turbines the most favourable is the blade element momentum theory due to its relative simplicity and usefulness (Ledoux et al. 2020). The assumptions that, the air flow is axisymmetric and that the rotor has infinite number of blades introduce losses in the BEM theory. The Prandtl's tip loss function corrects the effects due to the assumptions made (Ouakki and Arbaoui 2020).

The total power coefficient $\left(\mathrm{C}_{\mathrm{P}}\right)$ is calculated as an integral sum of all sectional power coefficients, described by Equation 1 (Manwell et al. 2010).

$$
\begin{aligned}
& \mathrm{C}_{\mathrm{P}}=\frac{8}{\lambda N} \sum_{i=k}^{N} \mathrm{~F}_{i} \sin ^{2} \varphi_{i}\left(\cos \varphi_{i}-\right. \\
& \left.\lambda_{\mathrm{ri}} \sin \varphi_{i}\right)\left(\sin \varphi_{i}+\lambda_{\mathrm{ri}} \cos \varphi_{i}\right)[1- \\
& \left.\left(\frac{\mathrm{C}_{\mathrm{D}}}{\mathrm{C}_{\mathrm{L}}}\right) \cot \varphi_{i}\right] \lambda_{r i}^{2}
\end{aligned}
$$

where $\mathrm{N}$ is the number of sections, $\mathrm{F}_{\mathrm{i}}$ and $\varphi_{\mathrm{i}}$ are the blade tip loss factor and blade angle, respectively, $\lambda_{\mathrm{ri}}$ and $\lambda$ are speed ratios at radial distance $r$ and tip of blade, respectively (Echjijem and Djebli 2020).

The chord length and twist angle profiles along the blade are obtained using Equations 2 to 6 provided by optimal rotor theory (Manwell et al. 2010).

$$
\begin{aligned}
\lambda_{\text {ri }} & =\lambda_{\text {design }}\left(\frac{r_{i}}{R}\right) \\
\varphi_{i} & =(2 / 3) \tan ^{-1}\left(\frac{1}{\lambda_{r_{i}}}\right) \\
\mathrm{c}_{\mathrm{i}} & =\frac{8 \pi r_{\mathrm{i}}}{\mathrm{BC}_{\text {Ldesign } \mathrm{i}}}\left(1-\cos \varphi_{\mathrm{i}}\right)
\end{aligned}
$$

$\theta_{\mathrm{T}, \mathrm{i}}=\theta_{\mathrm{p}, \mathrm{i}}-\theta_{\mathrm{p}, \mathrm{o}}$

$\varphi_{\mathrm{i}}=\theta_{\mathrm{p}, \mathrm{i}}+\alpha_{\mathrm{design}, \mathrm{i}}$

where $i$ is the blade section, $r_{i}$ is the distance from $i^{\text {th }}$ blade section. $C_{\text {Ldesign, }}, \lambda_{\text {design }}$ and $\alpha_{\text {design }}$ are the design lift coefficient, design tip speed ratio and design angle of attack, respectively. The other parameters are; $\theta_{\mathrm{T}, \mathrm{i}}$ is section twist angle, $\theta_{\mathrm{p}, \mathrm{i}}$ is section pitch angle and $\theta_{\mathrm{p}, \mathrm{o}}$ is a pitch angle at blade tip.

\section{Pressure distribution and pressure coefficient $\left(\mathbf{C}_{\mathbf{p}}\right)$}

The pressure coefficient is the ratio of the pressure forces to inertial forces which can be expressed as (Wang et al. 2007, Anderson 2010):

$\mathrm{C}_{\mathrm{p}}=\mathrm{dp} /\left(\rho \mathrm{v}^{2}\right)$

for the incompressible flow. Suppose a body flows in a fluid with pressure $\mathrm{p}_{\infty}$, dynamic pressure $\mathrm{q}_{\infty}$ and free stream velocity $\mathrm{v}_{\infty}$, and then consider any point on the body with velocity $\mathrm{v}$ and resulting into a pressure $\mathrm{p}$; using the Bernoulli's equation one obtains

$C_{p}=\frac{p-p_{\infty}}{q_{\infty}}=\frac{1 /{ }_{2} \rho\left(v_{\infty}^{2}-v^{2}\right)}{1 /{ }_{2} \rho v_{\infty}^{2}}$

Equation 8 can be simplified to

$\mathrm{C}_{\mathrm{p}}=1-\left(\frac{\mathrm{v}}{\mathrm{v}_{\infty}}\right)^{2}$

Also, from Equation 8 one obtains

$\mathrm{p}=\mathrm{q}_{\infty} \mathrm{C}_{\mathrm{p}}+\mathrm{p}_{\infty}$

From Equation 10 the value of $C_{p}$ tells how much $\mathrm{p}$ differs from $\mathrm{p}_{\infty}$ in multiples of the dynamic pressure $\mathrm{q}_{\infty}$.

The optimum rotor theory expressed by Equations 2-6 is used in this paper in developing an excel code to generate data for wind turbine blade modelling by SolidWorks software. The airfoils with 2D properties of high maximum lift coefficient, high lift-todrag ratio and a wide drag bucket were selected. Airfoil characteristics were examined by XFOIL software, to ascertain parameters required for small wind turbine blade. The computational fluid dynamics CFD software called Ansys CFX 17.2 was used in simulating the wind turbine rotor. 
The blade of the designed rotor had a total length of $3.56 \mathrm{~m}$ whereas it was divided into twenty elements. The first two elements were in circular form which is the root and comprise the hub of the rotor. The third element is the transition from the root to the aerodynamically shaped sections. The blade was divided into seventeen aerodynamically shaped sections which is a good number for smooth transition of chord length and twist angle distribution (Cencelli 2006, Chaudhary et al. 2014). The first three sections of the blade are formed by SG6042 airfoil because the airfoil is less cambered and has small gliding ratio, the $4^{\text {th }}$ to $17^{\text {th }}$ outer sections is made of SG6043 airfoil because it is highly cambered and it has high lift to drag ratio.

\section{Small wind turbine design parameters}

The design parameters of small horizontal axis wind turbine include the airfoil type, rotor diameter, design tip speed ratio, design wind speed and design angle of attack (Tang 2012).

\section{The design angle of attack (AoA)}

The determination of design angle of attack is related to the nature and number of airfoils used in the blade. The design angle of attack for single airfoil blade is that angle of attack at maximum ratio of $C_{L}$ to $C_{D}$ of the airfoil which is a critical angle of attack (Ahmed et al. 2011, Liu et al. 2013). The design angle of attack for a composite airfoil wind turbine has to be determined by investigation from several angles of attack. In this research, two types of airfoils were used for composite airfoil blade; hence five angles of attack from $3^{\circ}$ to $7^{\circ}$ were used to design five different rotor blades which were used for simulation to obtain the optimum design angle of attack. This research therefore investigated the optimal design angle of attack of the composite airfoil wind turbine blade for maximum power production.

\section{Design radius of the rotor and rated power}

The extracted wind power $\left(\mathrm{P}_{\mathrm{e}}\right)$ of the wind turbine is a subject of average wind speed and available wind power $\left(\mathrm{P}_{\mathrm{a}}\right)$ (Manwell et al. 2010). The design rotor radius
$\mathrm{R}=\sqrt{\frac{2 \mathrm{P}_{\mathrm{e}}}{\rho \pi \mathrm{V}_{\text {design }}^{3} \eta \mathrm{C}_{\mathrm{p}}}}$

where $C_{P}$ and $\eta$ are the power coefficient and the machine mechanical and transmission coefficients combined, respectively. The maximum extracted power $\left(\mathrm{P}_{\mathrm{e}}\right)$ is considered as a rated power for small wind turbines (Tenghiri et al. 2018).

\section{Design wind speed and rated wind speed}

The design wind speed as per IEA standard IEC 61400-2, must be taken as a product of annual mean wind speed $\mathrm{V}_{\mathrm{AMws}}$ and 1.4 (Manwell et al. 2010). The designed wind turbine is going to be used in Mbulu where the annual mean wind speed is $6 \mathrm{~m} / \mathrm{s}$ (Kainkwa 2000, Kibona 2020). Therefore, the design wind speed is calculated as $8 \mathrm{~m} / \mathrm{s}$. The rated wind speed in small wind energy system is normally taken as the design wind speed (Liu et al. 2013).

The Reynolds number $\left(\mathrm{R}_{\mathrm{e}}\right)$ exemplifies the airfoil performance with respect to free stream velocity (Gray et al. 2021)

$$
\mathrm{R}_{\mathrm{e}}=\frac{\rho \mathrm{Vc}}{\mu}
$$

where $\mu$ is the dynamic viscosity of the air, The $\mathrm{R}_{\mathrm{e}}$ of each section is between $3 \times 10^{5}-5$ $\times 10^{5}$ for small wind turbines; $4 \times 10^{5}$ is chosen as an average for the design $R_{e}$ (Winslow et al. 2018).

\section{Design rotor speed and tip speed ratio}

In order to control the noise issue the wind turbine blade tip speed should not exceed 70 $\mathrm{m} / \mathrm{s}$. In small wind turbine with low $R_{e}$ and optimum value of the ratio of $C_{L}$ to $C_{D}$, the tip speed ratio is taken between 6 and 8 (Singh et al. 2012). Equation 13 elaborates the effect of $\operatorname{TSR}(\lambda)$ on the turbine maximum power coefficient (Ge et al. 2016).

$\mathrm{C}_{\mathrm{Pmax}}=\left(\frac{16}{27}\right) \lambda\left[\lambda+\frac{1.32+\left(\frac{\lambda-8}{20}\right)^{2}}{\mathrm{~B}^{2} / 3}\right]^{-1}-\frac{(0.57) \lambda^{2}}{\frac{\mathrm{C}_{\mathrm{L}}}{\mathrm{C}_{\mathrm{D}}}\left(\lambda+\frac{1}{2 \mathrm{~B}}\right)}$ 13

\section{Wind turbine rotor design}

\section{Design parameters}

The wind turbine rotor design begins by selecting the rotor parameters. The parameters 
used in this study are listed in Table 1. The small wind turbine power was selected to be $5000 \mathrm{~W}$ which fits the weather condition of the site and it is for 3-4 rural household consumptions (Mwakitalima et al. 2021, Scott and Coley 2021). The design wind speed and radius of the rotor are as explained in small wind turbine design parameters section. The design power coefficient depends on profile drag that is $\mathrm{C}_{\mathrm{L}} / \mathrm{C}_{\mathrm{D}}$ and the tip speed ratio (TSR) which also is a function of number of blades. Given the TSR and number of blades and taking $C_{L} / C_{D}$ to be 100 the selected maximum $C_{P}$ is 0.5 . The design power coefficient is given by Equation 14 taking consideration other factors like mechanical efficiency (0.8) for conservative design (Azad and Kaysar 2012, Mulugeta and Gerawork 2017).

$C_{P \text { design }}=\left(C_{P}\right)_{\max } \times 0.8=0.5 \times 0.8=0.4$

The number of elements was taken as 20 for smooth transition of successive chord length and twist angle profile and to limit tedious work in blade modelling as explained methodology section of this paper. The design angle of attack is explained above whereas the air density is taken as $1.225 \mathrm{~kg} / \mathrm{m}^{3}$ as standard air density from sea level. The design lift coefficient $\left(\mathrm{C}_{\text {Ldesign }}\right)$ is taken from the highest $C_{L} / C_{D}$ ratio of the two airfoils that is SG6043 (Azad and Kaysar 2012).

\section{Airfoil selection and analysis}

The factor called thickness - to - camber ( $t / c)$ ratio has been identified as one of the criteria for selecting an airfoil for small wind turbine for high performance (Rehman et al. 2018). The curved airfoil with small thickness to camber ratio, tend to have high gliding ratio which is favourable for small wind turbine high performance (Osei et al. 2020). The polar curves characteristics of three airfoils (SG6041, SG6042, SG6043) are analysed using XFOIL at Re $=5 \times 10^{5}$. The two airfoils SG6042 and SG6043 are selected for wind turbine blade since they have high gliding ratios, high lift coefficients and minimum drag coefficient as shown from Figures 1 to 4 . The airfoils SG6042 and SG6043 have maximum thickness of $10 \%$ and maximum camber of $3.3 \%$ and $5.1 \%$, respectively. The gliding ratio and the aerodynamic stability of the stated airfoils are relatively high at wide span of angle of attack (Salgado et al. 2016).

Table 1: Wind turbine design parameters

\begin{tabular}{llll}
\hline Parameter & Symbol & Quantity & Units \\
\hline Rated power & $\mathrm{P}$ & 5000 & $\mathrm{~W}$ \\
Wind velocity & $\mathrm{U}$ & 8 & $\mathrm{~ms}^{-1}$ \\
Radius of rotor & & 3.56 & $\mathrm{~m}$ \\
Power coefficient & $\mathrm{C}_{\mathrm{p}}$ & 0.4 & \\
Number of blades & $\mathrm{B}$ & 3 & \\
Number of elements & $\mathrm{N}_{\mathrm{e}}$ & 20 & $\mathrm{kgms}^{-3}$ \\
Density & $\rho$ & 1.225 & \\
Tip speed ratio & $\lambda$ & 6 & degrees \\
Angle of attack & $\alpha$ & $3,4,5,6,7$ & \\
Lift coefficient & $\mathrm{C}_{\mathrm{L}}$ & 1.184 & \\
\hline
\end{tabular}




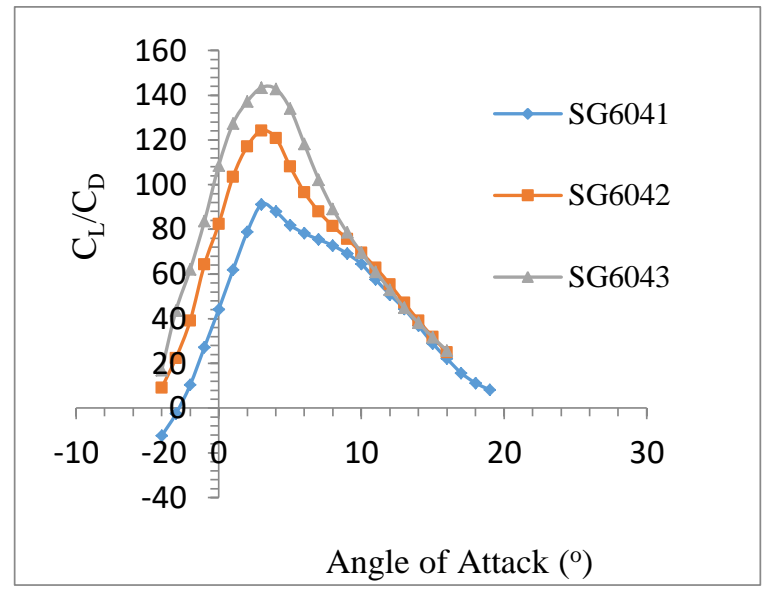

Figure 1: Gliding ratio against angle of attack for SG6041, SG6042 and SG6043.

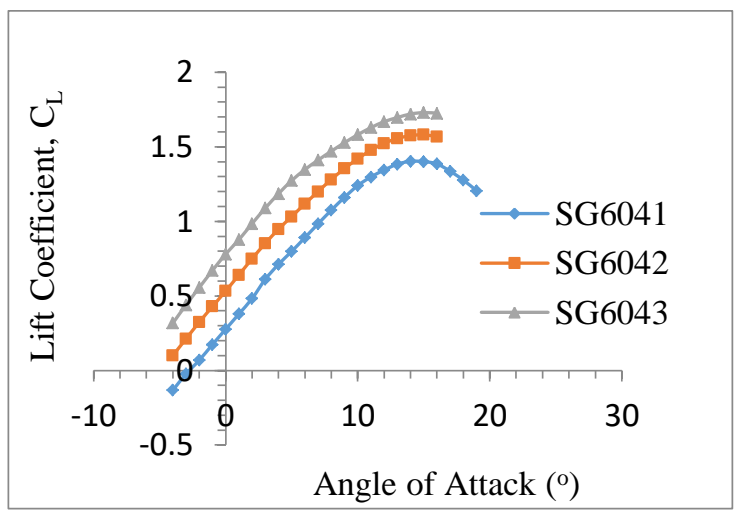

Figure 2: Lift coefficient against angle of attack for SG6041, SG6042 and SG6043 of Re = 5e5.

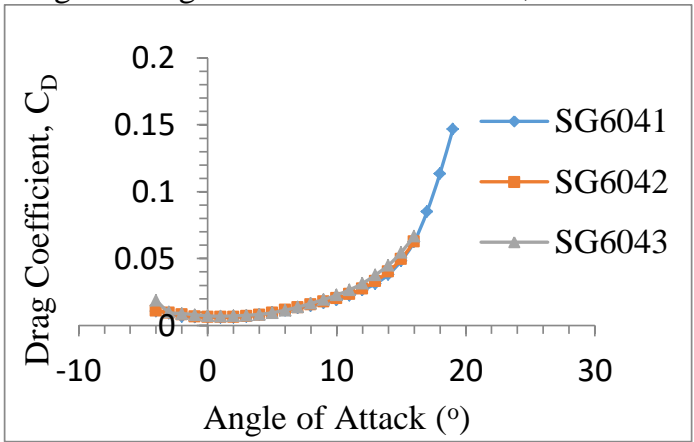

Figure 3: Drag coefficient against angle of attack for SG6041, SG6042 and SG6043 at Re = 5 e5. 


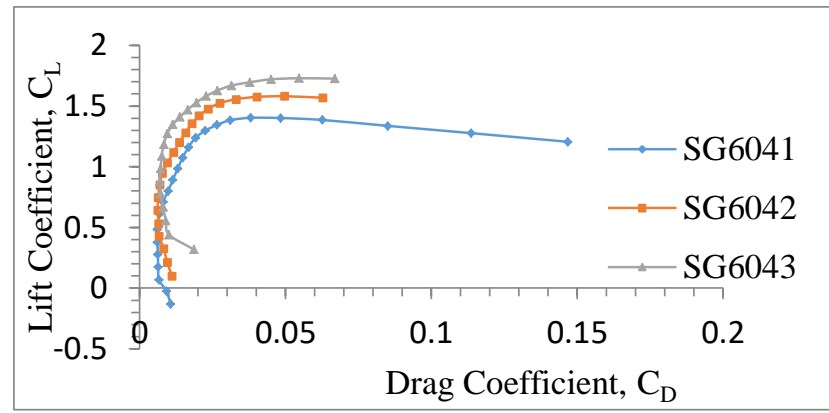

Figure 4: Lift coefficient against drag coefficient for $\mathrm{SG604X}$ at $\mathrm{Re}=5 \mathrm{e}$.

\section{CFD - rotor simulation}

In order to determine the optimal design angle of attack five blades were designed basing on design angle of attack of $3^{\circ}, 4^{\circ}, 5^{\circ}, 6^{\circ}$ and $7^{\circ}$. Each modelled blade was used to make a wind turbine rotor which was simulated using commercial computational fluid dynamics (CFD) software called Ansys CFX 17.2. The simulations were done for design wind speed of $8 \mathrm{~m} / \mathrm{s}$ and off-design wind speeds of $5 \mathrm{~m} / \mathrm{s}$ and $11 \mathrm{~m} / \mathrm{s}$ for comparison purposes in power performances. The other parameters for simulation were as shown in Table 1. The setup of the CFD simulations was as shown in Figure 5.

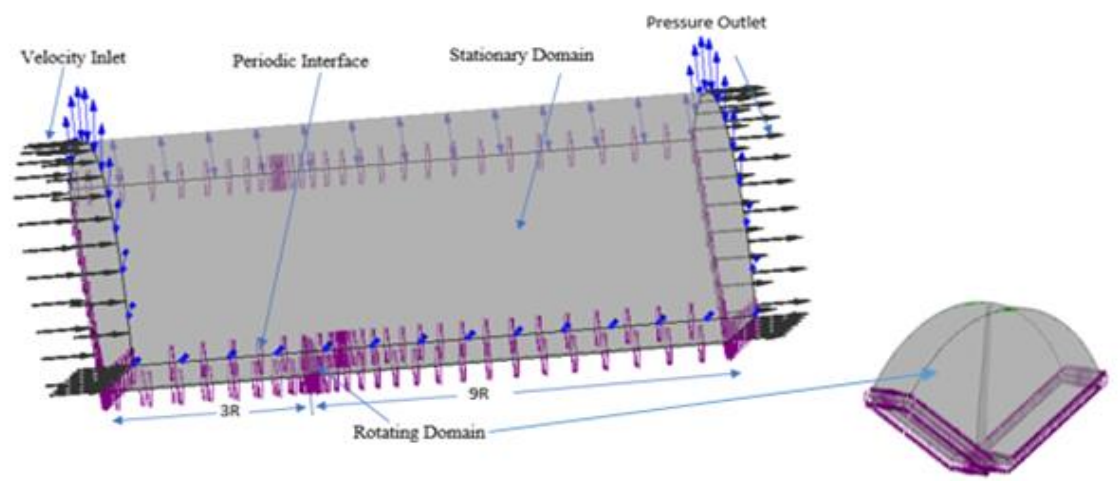

Figure 5: CFD simulation set up on Ansys CFX work bench.

\section{Results and Discussion}

The wind turbine designed and modelled had a constant chord length distribution for all five angles of attack whereas, the twist angle profile varied for all blades as shown in Figure 6 and Figure 7, respectively. The designed composite airfoil small wind turbine blades were modelled using SolidWorks software. Figure 8 is one of the wind turbine blades which was designed with design angle of attack of $5^{\circ}$.

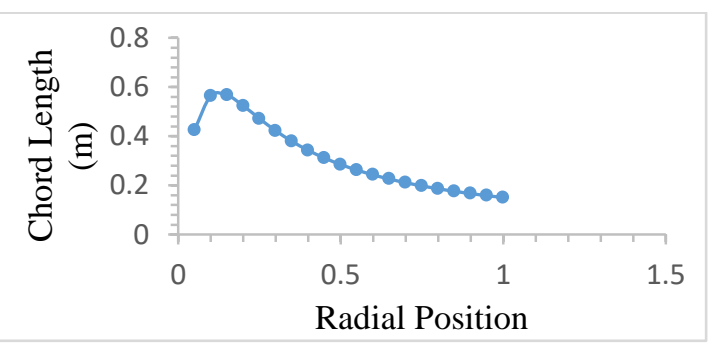

Figure 6: Radial chord length profile. 


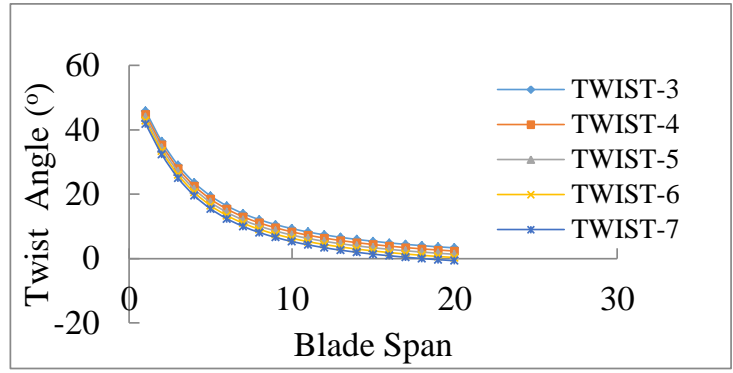

Figure 7: Radial twist angle profiles.

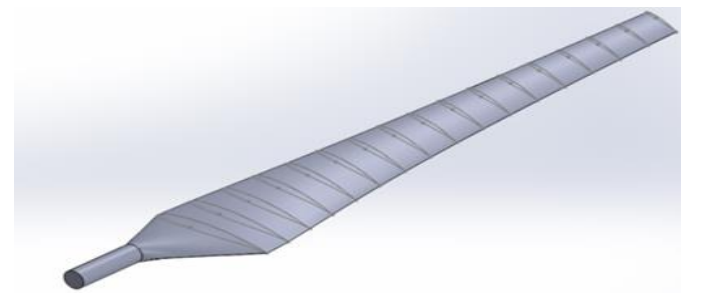

Figure 8: Wind turbine blade designed with an angle of attack of $5^{\circ}$.

The performance of the designed wind turbine rotors was optimised using design angles of attack and analysed by the CFD where four corresponding parameters were recorded during the wind turbine rotor simulations. The parameters were the power of the wind turbine $(\mathrm{P})$, the power coefficient $\left(\mathrm{C}_{\mathrm{p}}\right)$, the torque of the wind turbine $(\mathrm{Q})$ and the Y-plus $(\mathrm{y}+)$. The designed wind turbine rotors were also analysed for off-design performance at $5 \mathrm{~m} / \mathrm{s}$ and $11 \mathrm{~m} / \mathrm{s}$. The simulated wind turbine values recorded are shown in Table 2. The wind turbine rotors performances were compared to other wind turbine rotors with single airfoil blades and composite airfoil blades as discussed in the following paragraph.

A study of several airfoils for micro wind turbine of less than $1 \mathrm{~kW}$ and less than $1.2 \mathrm{~m}$ blade span was done by Q-blade; where SG6043 was revealed to be the best with power coefficient of 0.45 at $8.4 \mathrm{~m} / \mathrm{s}$ rated wind speed and the angle of attack was $14^{\circ}$ (Raut et al. 2017). Another study was done for a low Re airfoil AF300 which incorporated twist and taper; the highest power coefficient of a two bladed was 0.291 which was obtained at pitch angle of $18^{\circ}$ and wind speed of $6 \mathrm{~m} / \mathrm{s}$ (Singh and Ahmed 2013). The research was also done on small wind turbine with four blades made of NACA 2404; the maximum power coefficient obtained was 0.4 when the TSR was 2.7 and wind speed was $12 \mathrm{~m} / \mathrm{s}$ (Hirahara et al. 2005). Several airfoils were used in research for 0.5 $\mathrm{m}$ small wind turbine at $\mathrm{Re}$ of $0.5^{-1} \times 10^{5}$, NACA 2412 had maximum $C_{P}$ of 0.35 at TSR of 6 whereas, $S 2091$ had maximum $C_{P}$ of 0.39 at TSR of 6 and E216 had maximum $C_{P}$ of 0.43 at TSR of 6 (Chaudhary et al. 2020). A review was done on small wind turbines which showed that the highest power coefficient of small horizontal axis wind turbine was 0.45 (Tummala et al. 2016). The designed composite airfoil wind turbine blades have higher power coefficients compared with single airfoil wind turbine blades. The study of mixed airfoil blade of NACA 2412 and E216 showed that the $C_{P}$ of the mixed airfoil blade was superior to the blades of single airfoil, whereas; the mixed airfoil blade had $C_{P}$ of 0.45 at TSR of 6 and the $\mathrm{C}_{\mathrm{P}}$ of NACA 2412 and E216 airfoil blades were 0.43 and 0.42 , respectively (Chaudhary et al. 2020). The composite airfoil blades showed good aerodynamic performance, however with optimal design angle of attack in this study the performance has improved further.

Wind turbine rotors made of composite airfoil blades of SG6042 and SG6043 showed an improved performance of power coefficient $\left(\mathrm{C}_{\mathrm{P}}\right)$ of 0.457 as compared with those of single airfoil blades (Karthikeyan and 
Suthakar 2016). The hybrid of SG6042 and SG6043 airfoils with relative high maximum cambers produce consistent large pressure differences between the suction and pressure surfaces; as a result there is increased lift contribution from the pressure surface (Worasinchai et al. 2011).

The wind turbine is supposed to work at pre-stall condition, hence the design angle of attack must be selected at critical angle of attack; where $C_{L} / C_{D}$ ratio is maximum (Tang 2012). Since two airfoils are used for the blades, their optimal angle of attack is investigated within a range of probable angles of attack. The power coefficients for all wind turbine rotor blades designed ranged from 0.443 to 0.457 , whereas the highest power coefficient was observed at $6^{\circ}$ design angle of attack as shown in Table 2. The power performance results for off-design conditions did not deviate much from designated parameters. The power produced by designed wind turbine rotors ranged from $4966 \mathrm{~W}$ to $5258 \mathrm{~W}$ which is within the range of anticipated power. The torque of the designed wind turbine rotor ranged from $122 \mathrm{Nm}$ to $130 \mathrm{Nm}$. The torque corresponds with the applied radius of the rotor and the rotational speed of the rotor (rpm) (Singh and Gill 2020).

Table 2: CFD Simulation results for five rotors with different rotor blades

\begin{tabular}{llllll}
\hline $\begin{array}{l}\text { Angle of attack } \\
\left({ }^{\circ}\right)\end{array}$ & $\begin{array}{l}\text { Wind speed } \\
(\mathrm{m} / \mathrm{s})\end{array}$ & $\begin{array}{l}\text { Power } \\
(\mathrm{W})\end{array}$ & $\begin{array}{l}\text { Torque } \\
(\mathrm{Nm})\end{array}$ & $\begin{array}{l}\text { Power coeff. } \\
\mathrm{C}_{\mathrm{p}}\end{array}$ & $\begin{array}{l}\text { Y-plus } \\
\text { Y+ }\end{array}$ \\
\hline 3 & 5 & 1207.50 & 47.80 & 0.431 & 14.61 \\
& $8($ design$)$ & 5063.45 & 125.22 & 0.441 & 21.08 \\
4 & 11 & 13321.90 & 239.69 & 0.446 & 28.14 \\
& 5 & 1184.57 & 46.88 & 0.423 & 6.37 \\
& 8 (design) & 4966.90 & 122.84 & 0.433 & 9.20 \\
5 & 11 & 13053.9 & 234.83 & 0.437 & 11.73 \\
& 5 & 1232.05 & 48.76 & 0.439 & 14.48 \\
& $8($ design$)$ & 5165.36 & 127.75 & 0.449 & 21.03 \\
6 & 11 & 13586.60 & 244.42 & 0.454 & 28.13 \\
& 5 & 1260.04 & 49.88 & 0.449 & 17.59 \\
7 & $8($ design $)$ & 5258.86 & 130.06 & 0.457 & 26.03 \\
& 11 & 13808.90 & 248.46 & 0.461 & 35.65 \\
& 5 & 1219.81 & 48.29 & 0.435 & 12.44 \\
& $8($ design$)$ & 5129.18 & 126.85 & 0.446 & 17.92 \\
& 11 & 13510.80 & 243.09 & 0.452 & 23.68 \\
\hline
\end{tabular}

The values of lift-to-drag ratios at the roots of the blades are higher than at the tips and they tend to decrease gradually from roots to tips as shown in Figure 9 which is due to the blades tapering.

The power coefficient increases linearly from the root to the tip of the wind turbine blade as shown in Figure 10. The power coefficient near the tip is the highest which elucidates the importance of tapering the wind turbine blade to control the normal force on the blade which might be detrimental for blade due to fatigue. The maximum power coefficient is obtained in the tip speed ratios ranging from 6.4 to 7.6 as shown in Figure 11. 


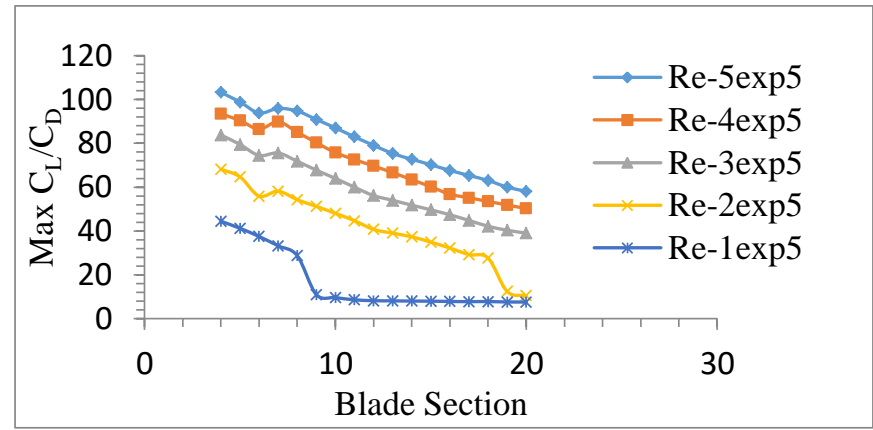

Figure 9: Blade span variation of maximum gliding ratios at $6^{\circ}$ angle of attack.

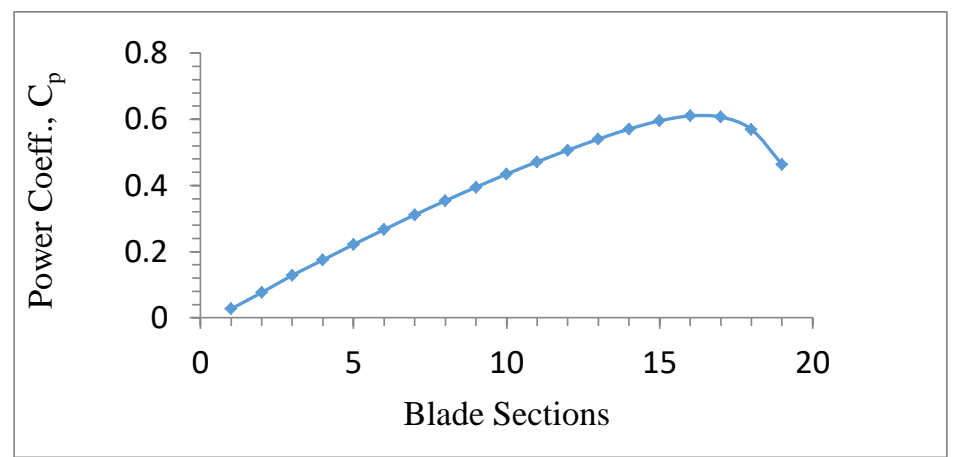

Figure 10: Radial distribution of power coefficient.

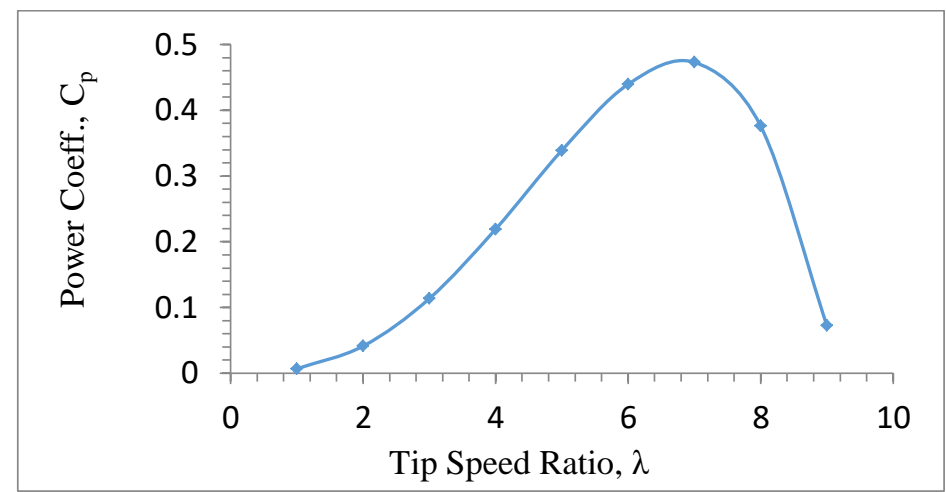

Figure 11: Power coefficient variation with tip speed ratio.

The pressure distribution on the surface of blades of all rotors was determined from CFD-Ansys CFX 17.2, at a position of $\mathrm{z}=$ 2.49. The pressure coefficients for pressure distribution of all five rotors are indicated in one set of axis of Figure 12, for comparison reasons. The pressure coefficients exhibit almost the same pattern, whereas higher angles of attack have absolute high-pressure coefficients. The pressure distribution on the suction side increases with greater slope from the stagnation point towards the trailing edge and from higher angle of attack to the smallest angle of attack. The value of the negative pressure coefficient on the upper (suction) side of the blade show that the static pressure is greatly below the atmospheric pressure as well the higher the pressure coefficient on the pressure side (lower) shows high static pressure which is above the atmospheric pressure as shown by Equation 
10. As a result, the lift force and hence blade rotation is enabled.

On the suction side (upper side) the pressure tends to have a maximum suction at $0.04 \mathrm{c}$, and then the pressure increases gradually towards the trailing edge. There is the possibility of separation bubble formation between $0.4 \mathrm{c}$ and $0.6 \mathrm{c}$ due pressure coefficient curves having humps. The results of pressure coefficients can be compared to the velocity contours (Figure 13). The pressure and velocity distributions on the surface of blades shown in Figure 13 from CFD simulations indicate the variations of contour pattern as the design angles of attack vary. The wind speed flow on the surface of the blades increases rapidly from stagnation point to the suction side in the leading edge and decreases towards the trailing edge. As the design angles of attack increase, the wind speed flow also increases in the leading edge and further decreases towards the trailing edge. The pressure distribution on suction surface of blades tends to decrease towards the leading edge and increases towards the trailing edge. The increase of the design angles of attack decreases further suction pressure, while the pressure on lower side remains relatively stable. Therefore, the design angle of attack influences the pressure differences between the pressure side and suction side which results into maximum lift force at an optimal design angle of attack. The figure captions are described like AoA$3 \mathrm{P}$ and AoA-3V, meaning the pressure and velocity at the angle of attack of $3^{\circ}$, respectively.

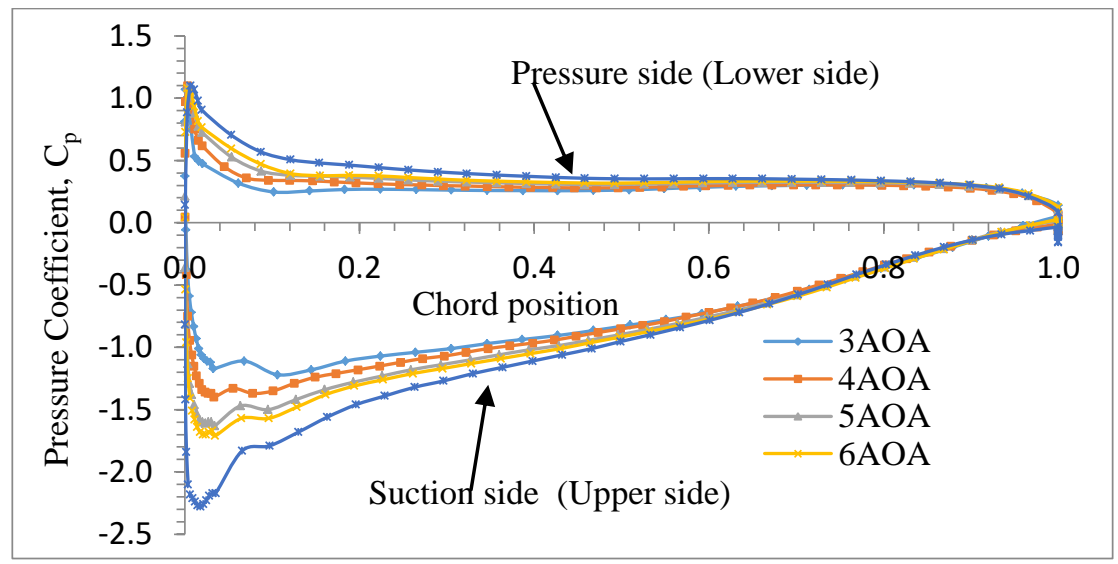

Figure 12: Pressure coefficients for five blades at $\mathrm{z}=-2.49$ at different angles of attack. 


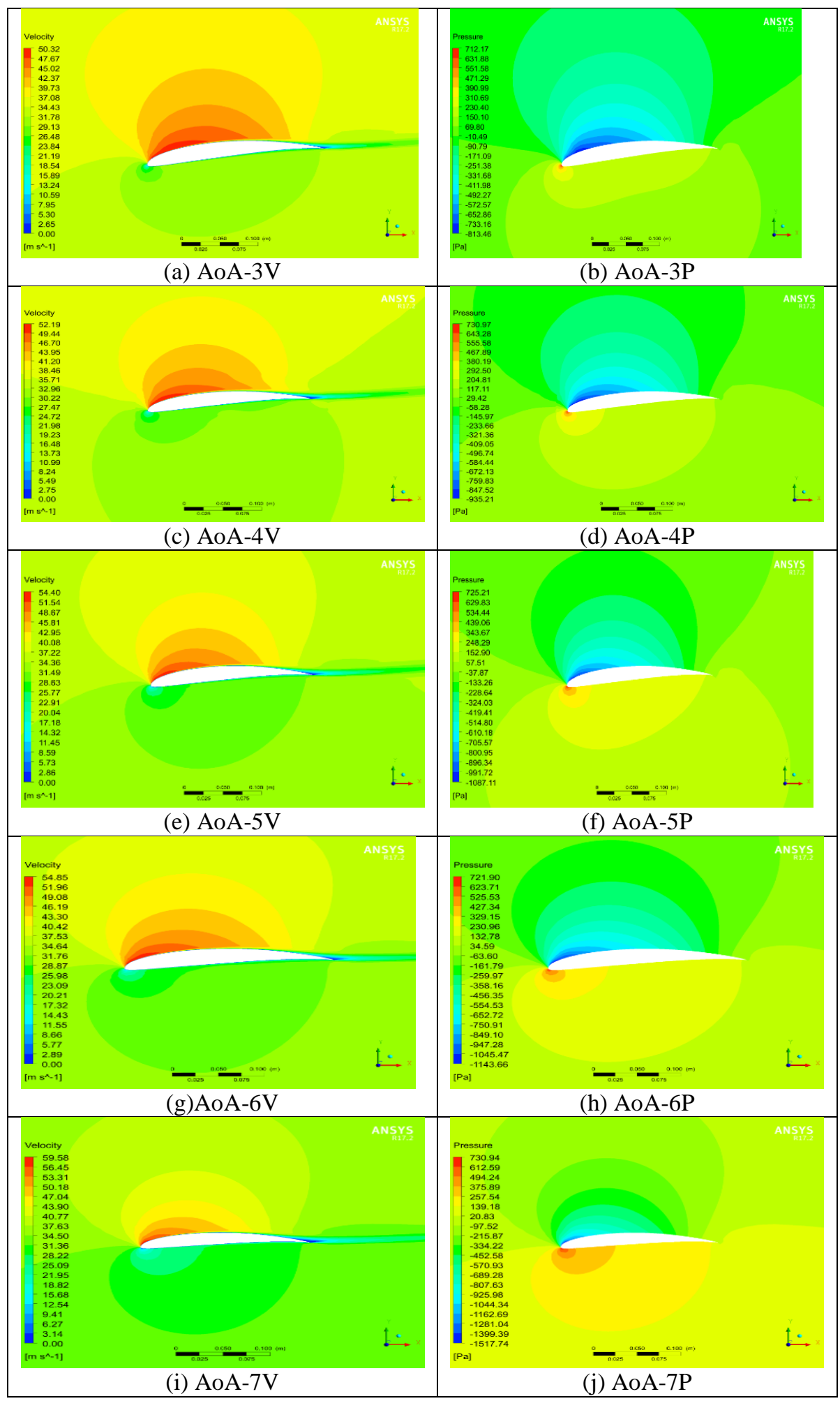

Figure 13: Velocity and pressure contour map for design angles of attack of $3^{\circ}-7^{\circ}$. 


\section{Conclusion}

The present work involved designing and investigation of a composite airfoil rotor blade and determining optimal design angle of attack for maximum power production. The SG6042 and SG6043 airfoils were selected based on their optimal airfoil properties for designing small horizontal axis wind turbine rotors. The airfoils have high maximum lift coefficients, high $\mathrm{C}_{\mathrm{L}} / \mathrm{C}_{\mathrm{D}}$ ratios and have a wide drag bucket. A 3.56 m radius wind turbine rotor was designed with the airfoils, whereas SG6042 formed the root and SG6043 formed the middle and outer parts of the rotor blades. The chord length and twist angle profiles of the blades were optimised using design angles of attack from $3^{\circ}$ to $7^{\circ}$. The analysis was done by $\mathrm{CFD}$. The rotor power, wind turbine power coefficients $C_{P}$, the wind turbine torque and the blades $\mathrm{Y}$-plus parameters were assessed for blades performance. All wind turbine rotors showed good performance in terms of the rotor power and rotor power coefficients, whereas, the rotor power ranged from $4966 \mathrm{~W}$ to $5258 \mathrm{~W}$ and rotor power coefficients ranged from 0.443 to 0.457 . The highest performance was shown by the rotor designed with design angle of attack of $6^{\circ}$ which is the optimum angle of attack. The enhanced wind turbine rotor instils good motives towards rural community electrification through renewable energy. The small wind turbine designed will be cheaper due to improved performance and hence socio-economic development may also pick up.

\section{Acknowledgement}

This research work was supported by the Water Infrastructures and Sustainable Energy Futures (WISE-Futures) centre of the Nelson Mandela African Institution of Science and Technology, Arusha Tanzania.

Conflict of interest: The authors declare no conflict of interest.

\section{References}

Ahmed MR, Narayan S, Zullah MA and Lee YH 2011 Experimental and numerical studies on a low Reynolds number airfoil for wind turbine blades. J. Fluid Sci. Technol. 6(3): 357-371.

Amir M and Khan SZ 2021 Assessment of renewable energy: Status, challenges, COVID-19 impacts, opportunities, and sustainable energy solutions in Africa. Energy Built Environ. In Press, doi: https://doi.org/10.1016/j.enbenv.2021.03.00 2

Anderson JJD 2010 Fundamentals of aerodynamics: $5^{\text {th }}$ ed, Tata McGraw-Hill Education, New York.

Azad AK and Kaysar MM 2012 Design of a horizontal axis wind turbine for electricity generation in low speed windy sites. Int. J. Adv. Renew. Energy Res. 1(6): 363-373.

Canale T, Ismail KAR, Lino FAM and Arabkoohsar A 2020 Comparative study of new airfoils for small horizontal axis wind turbines. J. Sol. Energy Eng. 142(4): 041004.

Castellani F, Astolfi D, Becchetti M and Berno F 2018 Experimental and numerical analysis of the dynamical behavior of a small horizontal-axis wind turbine under unsteady conditions: Part I. Machines 6(4): 52.

Cencelli NA 2006 Aerodynamic optimisation of a small scale wind turbine blade for low wind speed conditions. Master's dissertation, Stellenbosch University

Chaudhary MK, Prakash S, Kushawaha S, Gupta L, Humbre P and Patil AN 2020 Numerical and experimental analysis of a small horizontal axis wind turbine rotors. AIP Conf. Proc. 2311(1): 030002.

Chaudhary U, Mondal P, Tripathy P, Nayak SK and Saha UK 2014 Modeling and optimal design of small HAWT blades for analyzing the starting torque behavior. Eighteenth National Power Systems Conference (NPSC).

Dong H, Xia T, Chen L, Liu S, Cui YD, Khoo BC and Zhao A 2019 Study on flow separation and transition of the airfoil in low Reynolds number. Phys. Fluids 31(10): 103601.

Echjijem I and Djebli A 2020 Design and optimization of wind turbine with axial induction factor and tip loss corrections. Procedia Manuf. 46: 708-714.

El-Shahat A, Hasan MM and Abdelaziz AY 2019 Micro-small-scale horizontal axis wind 
turbine design and performance analysis for micro-grids applications. In: Bahrami S and Mohammadi A (Ed.), Smart Microgrids (pp 65-117), Springer, Cham, Switzerland.

Ge M, Tian D and Deng Y 2016 Reynolds number effect on the optimization of a wind turbine blade for maximum aerodynamic efficiency. J. Energy Eng. 142(1): 04014056.

Giguere P and Selig MS 1998 New airfoils for small horizontal axis wind turbines. J. Sol. Energy Eng.120(2): 108-114.

Gökgöz F and Güvercin MT 2018 Energy security and renewable energy efficiency in EU. Renew. Sustain. Energy Rev. 96: 226239.

Gray A, Singh B and Singh S 2021 Low wind speed airfoil design for horizontal axis wind turbine. Mater. Today: Proc.45: 3000-3004.

Habali S and Saleh I 2000 Local design, testing and manufacturing of small mixed airfoil wind turbine blades of glass fiber reinforced plastics: part I: Design of the blade and root. Energ. Convers. Manage. 41(3): 249-280.

Hansen TH 2018 Airfoil optimization for wind turbine application. Wind Energy 21(7): 502-514.

Hasan MM 2017 Design and performance analysis of small scale horizontal axis wind turbine for nano grid application. Master's Dissertation, Georgia Southern University

Hirahara H, Hossain MZ, Kawahashi $M$ and Nonomura Y 2005 Testing basic performance of a very small wind turbine designed for multi-purposes. Renew. Energy 30(8): 1279-1297.

Ighodaro O and Akhihiero D 2021 Modeling and performance analysis of a small horizontal axis wind turbine. J. Energy Resour. Technol. 143(3): 031301 (9 pages).

Jahanmiri M 2011 Laminar separation bubble: its structure, dynamics and control: Chalmers University of Technology.

Kainkwa RMR 2000 Wind speed pattern and the available wind power at Basotu, Tanzania. Renew. Energy 21(2): 289-295.

Karthikeyan N and Suthakar T 2016 Computational studies on small wind turbine performance characteristics. J. Phys. Conf. Ser.759: 012087.

Kibona TE 2020 Application of WRF mesoscale model for prediction of wind energy resources in Tanzania. Sci. Afr. 7: e00302.
Ledoux J, Riffo S and Salomon J 2020 Analysis of the blade element momentum theory. arXiv preprint, arXiv:2004.11100

Leloudas SN, Eskantar AI, Lygidakis GN and Nikolos IK 2020 Low Reynolds number airfoil family for small horizontal axis wind turbines based on RG15 airfoil. SN Appl. Sci. 2:371.

Liu X, Wang L and Tang X 2013 Optimized linearization of chord and twist angle profiles for fixed-pitch fixed-speed wind turbine blades. Renew. Energy 57: 111-119.

Ma J, Duan Y, Zhao MLW, Wang J, Meng KQ and Ren Y 2019 Effect of airfoil concavity on wind turbine blade performances. Shock.Vib. 2019, Article ID 6405153, 11 pages.

Manwell JF, McGowan JG and Rogers AL 2010 Wind energy explained: theory, design and application: John Wiley and Sons, UK

Mulugeta BA and Gerawork A 2017 Aerodynamic design of horizontal axis wind turbine blades. FME Trans. 45(4): 647-660.

Mwakitalima IJ, Rizwan M and Kumar N 2021 Standalone solar photovoltaic electricity supply to rural household in Tanzania. IETE J. Res. 1-16.

Naumann M and Rudolph D 2020 Conceptualizing rural energy transitions: Energizing rural studies, ruralizing energy research. J. Rural Stud. 73: 97-104.

Noronha NP and Krishna M 2021 Aerodynamic performance comparison of airfoils suggested for small horizontal axis wind turbines. Mater. Today: Proc. 46(7): 24502455.

Osei EY, Opoku RS, Albert KA and Muyiwa S 2020 Development of high performance airfoils for application in small wind turbine power generation. J. Energy 2020: 9710189.

Ouakki Y and Arbaoui A 2020 Accurate loads and velocities on low solidity wind turbines using an improved blade element momentum model. Wind Energ. Sci. Discuss. 2020: 1-30.

Park D, Shim H and Lee Y 2020 PIV Measurement of separation bubble on an airfoil at low Reynolds numbers. J. Aerosp. Eng. 33(1): 04019105.

Perić B, Simonović A and Vorkapić M 2020 Comparative analysis of numerical computational techniques for determination of the wind turbine aerodynamic 
performances. Therm. doi:10.2298/TSCI200216175P.

Raut S, Shrivas S, Sanas R, Sinnarkar N and Chaudhary M 2017 Simulation of micro wind turbine blade in QBlade. Int. J.Res. Appl. Sci. Eng. Technol. 5(4): 256-262.

Rehman S, Alam MM, Alhems LM, and Rafique MM 2018 Horizontal axis wind turbine blade design methodologies for efficiency enhancement-A review. Energies 11(3): 506.

Salgado V, Troya C, Moreno G and Molina J 2016 Airfoil selection methodology for small wind turbines. Int. J. Renew. Energy Res. 6: 1410-1415.

Scott N and Coley W 2021 Understanding load profiles of mini-grid customers in Tanzania. Energies 14(14): 4207.

Selig MS 2003 Low Reynolds number airfoil design lecture notes. von Karman institute for fluid dynamics, Belgium

Shah H, Bhattarai N, Lim C and Mathew S 2012 Low Reynolds number airfoil for small horizontal axis wind turbine blades. Sustainable Future Energy, and $10^{\text {th }}$ SEE forum, 2012, Brunei Darussalam.

Shin P, and Kim K 2020 Aerodynamic performance prediction of SG6043 airfoil for a horizontal-axis small wind turbine. $J$. Phys: Conf. Ser.1452(1): 012018.

Singh B and Gill HS 2020 Wind turbine blade design for low rotational inertia materials at variable speeds with different twisting angle using Q-Blade. Mater. Today: Proc.33(3): 1666-1670.
Singh RK, Ahmed MR, Zullah MA and Lee YH 2012 Design of a low Reynolds number airfoil for small horizontal axis wind turbines. Renew. Energy 42: 66-76.

Singh RK and Ahmed MR 2013 Blade design and performance testing of a small wind turbine rotor for low wind speed applications. Renew. Energ. 50: 812-819.

Tang X 2012 Aerodynamic design and analysis of small horizontal axis wind turbine blades. $\mathrm{PhD}$ thesis, University of Central Lancashire.

Tenghiri L, Khalil Y, Abdi F and Bentamy A 2018 Optimum design of a small wind turbine blade for maximum power production. IOP Conf. Ser. Earth Environ. Sci. 161: 012008.

Tummala A, Velamati RK, Sinha DK, Indraja V and Krishna VH 2016 A review on small scale wind turbines. Renew. Sustain. Energy Rev. 56: 1351-1371.

Wang JW, Jia RB and Wu KQ 2007 Numerical simulation on effect of pressure distribution of wind turbine blade with a tip vane. Int. J. Therm. Sci. 16(3): 203-207.

Winslow J, Otsuka H, Govindarajan B and Chopra I 2018 Basic understanding of airfoil characteristics at low Reynolds numbers $\left(10^{4}-10^{5}\right)$. J. Aircr. 55(3): 1050-1061.

Worasinchai S, Ingram G and Dominy R 2011 A low Reynolds number, high angle of attack investigation of wind turbine aerofoils. Proc. Inst. Mech. Eng. A 225(6): 748-763. 